\title{
LA MADRE DE ABŪ L-BARAKĀT AL-BALAFĪQĪ
}

\author{
MANUEla MARÍN \\ CSIC, Madrid
}

Al estudiar las anécdotas que, en la literatura árabe de $a d a b$, cuentan con la presencia de mujeres, F. Malti-Douglas ha observado una serie de constantes significativas. Suele suceder, en efecto, que la intervención de las mujeres se convierta en ejemplo depurado de agudeza de ingenio; sus réplicas silencian a menudo a sus oponentes masculinos o les asombran por su elocuencia y audacia ${ }^{1}$. Quizá la más conocida colección de dichos de mujeres sea la reunida por Ibn Abī Tāhir Tayfür (m. 280/893) en su Kitāb al-mantūr wa-l-manzūm, editada bajo el título de Balägat al-nis $\bar{a}^{\text {' }}$; sin embargo, muchos otros textos de $a d a b$, a lo largo de la historia de la literatura árabe, contienen en mayor o menor medida ejemplos del talento verbal de las mujeres y de su capacidad de improvisación poética.

En al-Ándalus, una de estas colecciones puede leerse en el tratado de hipología compuesto por Abū Muhammad ${ }^{\mathrm{c}} \mathrm{Abd}$ Allāh b. Abī 1-Qāsim Muhammad Ibn Ŷuzayy bajo el título Mațla al-yumn wa-l-iqbāl fí intiqā' kitāb al-ihtiffāl y dedicado a Muhammad V ${ }^{3}$. Como ya señaló hace tiempo G. S. Colin, «l'histoire des cinq jeunes filles arabes qui, s'étant réunies, se mirent à décrire chacune le cheval de son père, sert à l'auteur de transition pour amener une série

${ }^{1}$ Malti-Douglas, F., Woman's Body, Woman's Word. Gender and Discourse in Arabo-Islamic Writing, Princeton, 1991, 29 ss.

2 Existe una edición de El Cairo,1908, y otra más reciente de Beirut, 1987. Cf. Rosenthal, F., «Ibn Abī Tāhir Țayfür», E.I. 2, s.v.

${ }^{3}$ La obra ha sido editada con un antetítulo (Kitāb al-Jayl) por Muhammad al-Jaț̣ābī, Beirut, 1986. Sobre la producción de textos hipológicos y «paracaballerescos» en la Granada nașrí, cf. Viguera, M. J., «El ejército», El reino nazari de Granada (1232-1492). Política, instituciones. Espacio y economía. Historia de España Menéndez Pidal, VIII-III, Madrid, 2000, 457-59. Se desconoce la fecha de muerte de Ibn Ŷuzayy, que vivió a finales del s. VIII/XIV y era hijo del autor de al-Qawānin al-fiqhìya (sobre el cual, cf. Moral, C. del, y Velázquez Basanta, F.N., «Los Banū Ŷuzayy. Una familia de juristas e intelectuales granadinos del siglo XIV. I: Abū l-Qāsim Muhammad Ibn Ŷuzayy», $M E A H$ $45,1996,161-201)$.

Al-Qanțara XXIII, 1 (2002) 209-212 
d'anecdotes montrant la sagacité des femmes et leur éloquence» ${ }^{4}$. Se cuidó bien Ibn Ŷuzayy, con todo, de hacer notar cuán extraordinaria era esta situación:

\begin{abstract}
«este relato (hikāya) pertenece al capítulo de las cosas peregrinas relativas a la sagacidad y elocuencia (baläga) de las mujeres. El caso es que, a pesar de la cortedad de inteligencia y la limitación de ingenio que sufren casi todas las mujeres, en algunas aparecen muestras extraordinarias e imperecederas manifestaciones de eximia retórica, excelentes respuestas, indicios de mérito y testimonios de inteligencia. Nosotros mencionaremos - por la potestad de Dios Altísimo- algunas de estas excepcionales ocurrencias» ${ }^{5}$.
\end{abstract}

El no muy extenso repertorio de anécdotas reunidas por Ibn Ŷuayy termina con cuatro breves textos relativos a mujeres andalusíes, que se presentan, como es habitual, en relación a personajes masculinos. Con una excepción, todos estos breves relatos son bien conocidos y han sido utilizados por otros autores. Sus protagonistas femeninas son Umm al-Hanā', la hija de ${ }^{c}$ Abd al-Haqq b. 'Ațìya 6; la esclava Gāyat al-munà, que perteneció a al-Mu tașim Ibn Șumādiḥ ${ }^{7} \mathrm{y}$ la famosa poetisa granadina Nazhūn ${ }^{8}$.

La cuarta de las mujeres andalusíes mencionadas por Ibn Ŷuzayy como ejemplo de elocuencia es anónima. Se trata de la madre del famoso cadí Abū l-Barakāt Ibn al-Hāŷŷy al-Balafĩqī (m. 774/1372) ${ }^{9}$, que aparece en dos cortas escenas, ninguna de las cuales he podido localizar en otras fuentes. Tampoco he encontrado, hasta ahora, referencias a esta mujer que no sean las recogidas aquí por Ibn $\hat{Y}$ uzayy.

Una de las dos escenas descritas en esta obra sigue las mismas pautas que en los textos anteriormente señalados. Un hombre recita el primer hemistiquio de un verso, completado ágilmente por la mujer que lo escucha; o bien, un suceso inesperado hace surgir en la memoria de la mujer el recuerdo de un verso de otro autor. Más rara vez se debe al propio ingenio de la espectadora la composición de unas líneas poéticas que subrayan o enaltecen un hecho cualquiera. $\mathrm{Al}$ igual que Nazhūn, Gāyat al-munà o Umm al-Hanā', la madre de Abū l-Ba-

${ }^{4}$ Colin, G. S., «Un nouveau traité grenadin d'hippologie», Islamica VI (1934), 334.

5 Ibn Ŷuayy, Mațlac ${ }^{c}, 236$.

6 Id., p. 242. Cf. la traducción del texto y otras fuentes árabes que lo citan en Garulo, T., Dīwān de las poetisas de al-Andalus, Madrid, 1986, 13 (nota 8).

7 Garulo, T., Dìwān, 68.

${ }^{8}$ La misma anécdota, tal como la recoge al-Maqqarī, en Garulo, T., Dīwān, 111.

9 Cf. Gibert, S., «Abū l-Barakāt al-Balafiqūi, qādīi, historiador y poeta», Al-Andalus XXVIII (1963), 381-424 y Puente, C. de la, «La familia de Abū Isḥāq Ibn al-Ḥâŷŷy de Velefique», $E O B A \mathrm{~V}$ (Madrid, 1992), 309-347. 
rakāt es capaz de responder imaginativamente al reto lanzado por un contrincante masculino ${ }^{10}$. Nada hay de extraordinario en ello, pero sí es notable el hecho de que, gracias a esta escena, puede identificarse el entorno familiar de la madre de Abū l-Barakāt. En efecto, quien quiso comprobar su capacidad de improvisación era su primo materno, el literato Abū Zakarīyā' Yahyà b. Zarqāluh ${ }^{11}$.

Gracias a los estudios de S. Gibert sobre Ibn Jātima, la identificación de Yahyà b. Zarqāluh no ofrece dificultad. Pertenecía este personaje a la misma familia que Abū Ŷa far Aḥmad Ibn Zarqāluh, el discípulo de Ibn Jātima que recogió sus versos ${ }^{12}$. De Yahyà $b$. Zarqāluh (686-750/1287-1349) se conservan algunos fragmentos poéticos, traducidos también por S. Gibert ${ }^{13}$. Ibn al-Qādì le da su nombre com-

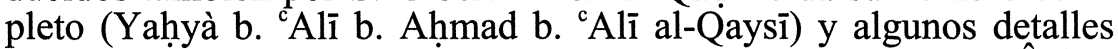
biográficos: era literato, poeta, $k \bar{a} t i b$ y fue sustituto del $q \bar{a} \bar{d} \bar{i} \mathrm{Abu} \hat{\mathrm{Y}} \mathrm{a}^{\mathrm{c}} \mathrm{far}$ b. Yabal en la Ajarquía de Almería 14. Esta familia de los "Banū Zarqāluh" estaba vinculada claramente a Almería ${ }^{15}$ y pertenecía a las elites socioculturales, entre las cuales se establecían a menudo redes de parentesco basadas en el matrimonio; no es nada excepcional, desde luego, esta alianza entre los Zarqāluh y los Banū l-Hāâŷy ${ }^{16}$.

En las familias de ulemas era también usual que algunas mujeres recibiesen una esmerada educación ${ }^{17}$. De ese modo, cuando Ibn Zarqāluh pide a su prima que complete este verso:

Ojos míos, que abrumáis a mi corazón con su mirada.

ella es capaz de improvisar:

Ojalá os cerréis para no soportarla.

${ }^{10}$ Cf. Garulo, T., «La poesía femenina en árabe clásico y la expresión de los sentimientos», Medievalia 27 (1998), 26-37.

${ }^{11}$ Ibn Ŷuzayy, Mațlac 243.

12 Gibert, S., «Una colección de "tawriyas” de Abu Ğac far Ahmad Ibn Hātima», Études d'orientalisme dédiées à la mémoire de Lévi-Provençal II (Paris, 1962), 543-57. Véase también Ibn al-Jațīb, Nufädat al-ŷirāb, III, ed. S. Fāgiya (Casablanca, 1989), 323-5 y nota 84 (p. 340).

${ }_{13}$ En Poetas árabes de Almería (s. X-XIV), Almería, 1987, 207-211.

${ }^{14}$ Ibn al-Qādịi, Durrat al-hîyâl, El Cairo, 1970, n. ${ }^{\circ} 1446$.

15 Otro personaje del mismo grupo familiar, algo anterior en el tiempo, es señalado en Gibert, S., «Una colección de "tawriyas"», 546.

16 Sobre este fenómeno, cf. Marín, M., «Parentesco simbólico y matrimonio entre los ulemas andalusíes», Al-Qanțara XVI (1995), 335-356.

17 Cf. Ávila, M. L., «Women in Andalusi Biographical Sources», Writing the Feminine: Women in Arab Sources, M. Marín y R. Deguilhem (eds.), Londres (en prensa), 149-163. 
y de añadir, por cuenta propia:

Me han infligido un castigo infinito, sobre el que no hace falta extenderse ${ }^{18}$.

Además de su preparación poética, la madre de Abū l-Barakāt había sido educada en ciencias menos profanas, como puede observarse en la segunda de las escenas que protagoniza y que, como la anterior, fue transmitida por su hijo:

«Llegó a Almería una mujer predicadora, que daba sermones a las mujeres. Mucho de lo que decía se le censuraba. Dijo: llegó noticia de esta mujer a la madre del qãḍ̂̉ Abū l-Barakāt, a la cual se le describió su forma de actuar. Entonces ella dijo: Dios Todopoderoso es verídico: "cuando se pronuncie contra ellos la sentencia, les sacaremos de la tierra una bestia que proclamará"»" ${ }^{19}$.

La actividad de mujeres predicadoras en al-Ándalus está muy mal documentada, pero se conoce, al menos, el nombre de una de ellas - Rašīida al-Wāeciza-, cuya actividad itinerante por todo al-Ándalus sólo mereció alabanzas ${ }^{20}$. Nada se sabe de las razones por las cuales se censuró a la anónima predicadora llegada a Almería, aunque la vehemente reacción de la madre de Abū l-Barakāt hace suponer que su conducta o sus sermones no se correspondían con los criterios religiosos de una familia de buena posición y alto nivel cultural. La presencia de esta predicadora en Almería, no obstante, contribuye a completar algo más el cuadro, siempre muy fragmentario, de la piedad de las mujeres andalusíes y confirma la existencia de formas propias de expresión religiosa. En los labios de la madre de Abū 1-Barakāt, la fuerte censura a estas prácticas es significativa de la desconfianza de los ulemas hacia fórmulas piadosas que escapasen a su control, pero también sirve para retratar a una mujer que es capaz de citar adecuadamente el Corán, representando un nivel de conocimientos superior al de quienes acuden a escuchar las exhortaciones de la predicadora.

Las dos pequeñas viñetas en las que aparece la madre de Abū l-Barakāt al-Balafíqī no sólo documentan su personalidad, sino que la sitúan en un contexto sociocultural muy bien definido. Relaciones de parentesco y méritos personales la convirtieron en un modelo de conducta y sabiduría, que su hijo contribuyó a difundir ${ }^{21}$.

18 Ibn Ŷuzayy, Mațla ${ }^{c}$ p. 243. Metro basiț.

19 Idem, p. 242-3. La aleya, en Corán, XXVII, 82

20 Marín, M., Mujeres en al-Ándalus, Madrid, 2000, 625-6.

${ }^{21}$ Sobre otras mujeres en la familia de Abū l-Barakāt, cf. Marín, M., Mujeres en al-Ándalus, 452 y 467. 